\title{
Communication Strategies for Reducing Patient Anxiety in Pedodontics Dentistry
}

\author{
Jim Schnell* \\ Professor, Kutztown State University, USA
}

*Corresponding author: Jim Schnell, ODU Professor of Communication Studies,

Kutztown State University, Pennsylvania, USA.

Received Date: February 07, 2019

Published Date: February 21, 2019

\section{Introduction}

This article will discuss the use of selected communication behaviors for reducing the level of anxiety experienced by child dental patients. The main areas to be covered are communication within dentistry, communication with children in the dental environment, and approaches for reducing anxiety experienced by child dental patients.

Dentists comprise the second largest group of primary, directservice health practitioners in the country [1]. Little has been written on communication between dental professionals and their patients, in comparison with other primary health care areas. Dental communication is unique, in comparison with other health care areas, as there is a lack of urgency in everyday interactions. Dental care is rarely a matter of life and death [2].

A problem more prevalent in dentistry than in most of medicine is pain, or more specifically, the fear of pain. This reaction to dental work is partially one of fear of the unknown, which may include pain. This problem is complicated as many people don't go to see a dentist unless he/she has a problem, which is much more likely to result in pain when treated. Thus, a self-fulfilling prophecy can occur [3]. One study of dental patients indicates pain, and the equipment usually associated with pain, accounts for $62 \%$ of patient fears [4].

Communicating with children in health care settings, specifically the dental environment, poses a variety of considerations for the dental team. These considerations include the health care environment, the age of the child, interpersonal relationships, and helping children understand their dental experience.

Mark Knapp has researched the strong effect physical context has on human communication. The physical setting can exert a powerful influence on interaction by affecting expectations of patients and providers and inhibiting their exchanges [5]. Dental offices can be very frightening to children. They are comprised of unfamiliar people, strange instruments and equipment, unpleasant sounds, and are often decorated in a manner which creates a stark, sterile, and cold atmosphere.

Obviously, all stressful aspects of the dental office cannot be eliminated, but some helpful approaches can serve to dilute fears. Unfamiliar people can be identified by title and name. Equipment can be decorated with mobiles and artwork, or they can be placed out of sight until they are needed. Cheerful pastel colors can be used to replace antiseptic white walls. Children's art work can be displayed on walls for viewing from the dental chair, and toys and books can be placed in waiting areas [6-8].

The age of the child is also a consideration. Children ages one to five years frequently exhibit the most difficulty with health care experiences. Researchers suggest this is due to three primary reasons: (1) the child is separated from the parents, (2) young children have a more pronounced sensitivity to pain and an inability to deal with fears, and (3) young children do not have strong reality concepts and therefore are subject to grotesque fantasies [9]. The dental team can help compensate for these vulnerable areas by making special efforts to provide young children with additional emotional support.

The dental team cannot be expected to replace the support group of a child, but researchers have found the establishment of positive interpersonal relationships between health professionals and pediatric patients can help reduce the threat experienced by children in health care environments [10]. Such relationships with children can be initiated by talking with them about general topics of interest such as movies, sports, pets, and hobbies. Caring feelings are essential in providing for the emotional needs of patients. Through communication, caring feelings are translated into caring behavior. Research indicates practitioners' displays of caring and warmth can increase patient satisfaction [11]. and increase patient compliance with treatment [12]. 
A considerable amount of research indicates child understanding of health care experiences reduces emotional upset [13]. Possibilities for misinterpretations are fostered when the child does not understand procedures, he/she is being subjected to. Researchers have found children frequently interpret illness as punishment for wrong doing [14]. and health care procedures can be interpreted as hostile, mutilating acts [15]. It has been shown that a practitioner's explanations of procedures improve patient compliance [16]. Thus, the dental team would be well advised to explain, in understandable terms, a basic description of what the child will be experiencing.

When appropriate, the use of humor can also be employed to alleviate anxieties. A study, entitled "Joking Under the Drill", indicates the use of humor may reduce the subjective experience of stress [17]. The author found those patients who exhibited jokinglaughter behaviors rated their dental experiences as being less stressful.

The dental team should be aware of the content and relationship conveyed in communication. That is, when a dentist interacts with a patient, messages occur on two levels: content and relationship. Thus, a verbal message not only provides information, it also defines the relationship of the interactants. This relationship is defined through elements such as tone of voice, body movements, eye behavior, and other nonverbal areas [18].

Nonverbal communication is widely accepted as being more influential than verbal communication. When nonverbal messages contradict verbal messages, the nonverbal messages will be believed over verbal messages [19]. It is imperative for dental team members to be aware child dental patients interpret both their verbal and nonverbal messages. These nonverbal messages are sent through a variety of behaviors: including artifacts, kinesics, occulesics, tactilics, proxemics, and chronemics.

Artifacts refer to our personal appearance. Such considerations include clothing, jewelry, and hair style. In the past decade, the traditional white uniforms female dental team members generally wear have been substituted by some with less formal types of clothing. Regardless, clothing sends a message (good or bad) which affect patient observations. One recent study indicates the traditional white uniform is becoming the preferred uniform again. This is due to perceived professionalism and efficiency [20].

Kinesics deals with body movements and posture. Body movements and posture can convey listener interest, involvement, and alertness. In working with children, it is important to request changes in body movements and posture in a way which ensures their understanding of why he/she is being asked to change positions. For instance, being leaned back in a dental chair or being sat up to rinse his/her mouth [21].

Oculinids involves facial and eye movements. The face and eyes are primary sources of emotional information for patients. Dental team members should be aware of facial and eye movements they are presenting as patients often watch the face of who is working on them. If the dental team member occulesically communicates fear, anger, or disgust, the patient will most likely interpret this. Friendly facial and eye expressions help to accommodate the patient, just as friendly conversation.

Dactylics refers to touching behaviors and is one of the more intimate channels of human communication. Dental team members can communicate empathy with touch, or they can communicate aversion through insensitive touching behavior.

Touching behavior is especially important when the patient is having his/her teeth worked on. Practitioners suggest a variety of methods for alleviating child patient fears of injections, drilling, and polishing. For example, one approach before cleaning teeth is to polish a fingernail of the patient to show what the instrument will feel like. Injections can be given less painfully by rubbing the gum prior and during the injection. Children may also want to hold (or squeeze) the hand of a dental team member. In each situation, touching behaviors can benefit the patient.

Chronemics deals with the use of time. Dental team members should be sensitive to the amount of time patients spend in waiting rooms, dental chairs, and being worked on while in the dental chair. Making a child patient wait for dental treatment can increase that patient's anxiety level. Empathy with the patient can be an appropriate guide for chronemic concerns.Proxemics involves the use of space and distancing.

Practitioners have to infringe on cultural territoriality norms when working on patients. This closeness can cause patient discomfort. When possible, the dental team member should give the patient time and space, between phases of dental treatment, to allow him/her to feel spatial privacy.

It is important for dental team members to remember the aforementioned factors, verbal and nonverbal, are perceived in concert, rather than individually. Practitioners should strive to be aware of the messages they are sending and ensure these messages do not contradict each other. In situations where the patient is unaware of dental procedures, as is frequently the case with children, dental team members can make the difference between a positive or negative experience.

\section{Aknowledgment}

None.

\section{Conflict of interest}

No conflict of interest.

\section{References}

1. WO Young, L Smith (2015) The nature and organization of dental practice. In H. Freeman, Handbook of Medical pp. 231-240.

2. TL Thompson (2012) Communication for Health Professionals p. 88.

3. Thompson p. 90.

4. WE Arnold, Communication Patterns of Dentists with Their Patients. Unpublished paper.

5. Knapp ML, Judith A Hall (2000) Nonverbal Communication in Human Interaction.

6. Klinzing D (2005) Communication for Allied Health Professionals pp. 199.

7. Robertson J (1962) Hospitals and Children. 
8. DM Levy (1945) Child patients may suffer psychic trauma after surgery. Modern Hospital 65: pp. 51-52.

9. A Chapman, D Loeb, M Gibbons (1956) Psychiatric aspects of hospitalizing children. Archives of Pediatrics,73: 77-78.

10. HG Dimock (1962) The child. In hospital Davis, Rothman PE (Eds.), A note on hospitalization, USA, 995-999.

11. BJ Doyle, JE Ware (1977) Physician conduct and other factors that affect consumer satisfaction with medical care. J Med Educ 5(10): 793-801.

12. E Caplan, M Sussman (1966) Rank order of important variables for patient and staff satisfaction with Outpatient Service. Journal of Health and Human Behavior 7(2): 133-137.

13. JA Wolfer, MA Visintainer (1957) Pediatric surgical patients' and parents' stress responses and adjustment as a function of psychological preparation and stress point nursing care. Nursing Research24(4): 244255.

14. H Gofman, W Buckman, G Schade, The child's emotional response to hospitalization. American Journal of Diseases of Children, 93(2): 157164.
15. E Gellert (1958) Reducing the emotional stresses of hospitalization for children. American Journal of Occupational Therapy12(3): 125-129.

16. F Erickson (1958) Play interviews for four-year-old hospitalized children. Monographs of the Society for Research in Child Development23(3): pp. $1-77$.

17. SD Lane, Communication and patient compliance. In Pettegrew LS, Arntson P, Bush D, Zoppi K (eds.), Straight Talk: Explorations in Provider and Patient Interaction.

18. AD Trice (1986) Joking under the drill: A validity study of thecoping humor scale. Journal of Social Behavior \& Personality1(2): 265-266.

19. WW Wilmot Dyadic (2014) Communication.

20. Knapp (2000).

21. GE Gordon, JE Dugan, EM Wilcox, JR Wilcox (1986) Communicating with patients: Messages from nursing uniforms. Paper presented at the Communicating with Patients. Conference: p. 6. 